Né en Bourgogne il y a quelques soixante ans, André Lagrange est poète, essaiste et critique. Arrivé à Paris dans sa prime adolescence, il poursuivit des études de Lettres avant de s'orienter vers la pratique du journalisme. A cette occasion, il se spécialisa dans l'interview des écrivains célèbres: Eluard, Cendrars, Lanoux, Sabatier... André Lagrange a également signé dans différentes revues littéraires des articles de critique et de réflexion concernant des auteurs et des peintres, ce qui ne l'empêcha de poursuivre la publication de son oeuvre personnelle.

\title{
$\nLeftarrow \%$
}

L'océan... longue respiration de ses îles mortes, abandonnées telles des barques d'émeraude. Les vents creusent un reflux à travers quoi le batelier (mesure d'alerte) tire les voiles enroulées sur leurs drailles. La vague, une fois encore, assiège le flanc des navires avec un grincement doux / comme un rêve de femme... Pourquoi dit-on "battre le rivage," quand il s'agit de vergues en croix - espars sur l'avant des mâts - fuyant un horizon crépusculaire...

L'homme en négatif, prisonnier de son langage. Contrainte et dégoût à travers une existence où chaque débord serait interdit. Une échappatoire à partir de l'intellect - ou de tout acte de révolte entraînerait... l'imprévisible, a-t-on fait comprendre à son procès! Il lui reste à subir un enchaînement d'idées, de circonlocutions - avec le hasard comme agent double. A certains moments, il aimerait faire intervenir... quelques mots de passe / des formulaires connus de tous, lui permettant de structurer tels discours, telles brillantes causeries. Mais toutes approches deviennent, rapidement, illusoires.

Se dilue, par-delà son imagination, un "désert mental" que personne n'aura obligation de reconnaitre. 
Indifférence de la ville aux lumières de l'été... Les cortèges (sous un éventail de pluie) se déplaçatent dans un demi-jour peu propice aux démonstrations. Les ruelles, fleuries de tournesols, ne s'ouvraient plus que pour les indigents ne sachant où disperser le trésor de la veille. A l'angle des barraquements, un bruit indéfinissable grondait par à-coups - sans que l'on imagine si le silence eut été préférable... L'on se prenait à entendre quelques fanfares, quelques orgues de plein vent; néanmoins l'horizon, inaccessible à ce point de la ville devenue étrange par ses coloris, brouillait les perspectives pour le vagabond ignorant des lieux.

L'intervalle... se rappelle-t-on ce qui existait avant... entre la vigilance du regard et l'éclipse de cette chose (objet?) désormais disparue... Que recèlent l'arbre et la pierre quand le multiple de notre vision les abandonne pour un temps - se peut-il que l'espace / engendré par quelques signes d'intelligence / se remplisse, se structure avec des variations inconnues à ce jour. Les liens (tissés de longue haleine) entre l'agglomérat et l'homme se consument, ainsi qu'énigme en devenir. Résonance dans l'immobilité! Plus tard, s'opérera un lent mouvement d'approche ... sans que l'on y prenne garde. Les parties (jusque-là invisibles) entre le négatif et le positif s'assembleront à travers des jeux d'ombre et de mystère.

$\mathrm{Ne}$ restera plus au voyageur étranger qu'une multiplication frénétique des heures.

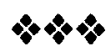

Essayer de se dégager... mais de quoi? Brusques tâtonnements de mémoire à travers un langage qui bientôt deviendra inaudible. Ne plus admettre (craindre?) les aliénations soumises au jugement de chacun. Avant tout: ne pas se laisser surprendre. Répéter - inlassablement - les gestes de l'enfance: maintenir en soi (hors de soi) cet organisme, constitué de braises et de cendre, qui fut le nôtre jusqu'alors.

Et puis... attendre... A l'instant révolu, déposer le masque! 